\section{Remote Sensing of Canopy Cover in Horticultural Crops}

Thomas J. Trout ${ }^{1}$

USDA-ARS, Water Management Research, 2150 Centre Drive, Building D, Ft. Collins, CO 80526

\author{
Lee F. Johnson \\ CSUMB/SEP, Earth Science Division, NASA/ARC 242-4, Moffett Field, \\ $C A 94035$
}

Jim Gartung

USDA-ARS, Water Management Research, 9611 South Riverbend Avenue, Parlier, CA 93548

Additional index words. evapotranspiration, shaded area, NDVI, vegetation index, fractional cover, crop coefficients

\begin{abstract}
Canopy cover (CC) is an important indicator of stage of growth and crop water use in horticultural crops. Remote sensing of $\mathrm{CC}$ has been studied in several major crops, but not in most horticultural crops. We measured $C C$ of 11 different annual and perennial horticultural crops in various growth stages on 30 fields on the west side of California's San Joaquin Valley with a handheld multispectral digital camera. Canopy cover was compared with normalized difference vegetation index (NDVI) values calculated from Landsat 5 satellite imagery. The NDVI was highly correlated and linearly related with measured $\mathrm{CC}$ across the wide range of crops, canopy structures, and growth stages $\left(R^{2}=0.95, P<0.01\right)$ and predicted $C C$ with mean absolute error of 0.047 up to effective full cover. These results indicate that remotely sensed NDVI may be an efficient way to monitor growth stage, and potentially irrigation water demand, of horticultural crops.
\end{abstract}

Horticultural and other specialty crops, although grown on a relatively small cultivated area, provide nearly $50 \%$ of the crop sales value in the United States (NASS, 2002). The growth stages and phenology of many horticultural crops are not well studied and tend to be difficult to generalize as a result of wide variations in varieties, planting densities, and cultural practices. Growth stage and crop size is especially important for horticultural crops because canopy light interception is a primary determinant of crop water requirement and most horticultural crops are grown with irrigation in water-short areas.

Fractional canopy cover (CC) is a relatively easily measured property that is a good indicator of light interception. Several studies have related crop water use to CC (Grattan et al., 1998; Johnson et al., 2004; Trout and Gartung, 2006; Williams and Ayars, 2005). Accurate and efficient estimation of actual $\mathrm{CC}$ would allow improved scheduling and allocation of irrigation water (Bausch, 1995; Hunsaker et al., 2005; Neale et al., 2005).

Received for publication 10 Sept. 2007. Accepted for publication 19 Oct. 2007.

Mention of a trademark, proprietary product, or vendor does not constitute a guarantee or warrantee of the product by the U.S. Department of Agriculture and does not imply its approval to the exclusion of other products or vendors that also may be suitable.

${ }^{1}$ To whom reprint requests should be addressed; e-mail Thomas.Trout@ars.usda.gov
Previous studies have shown that various spectral vegetation indices, calculated from visible and near-infrared (NIR) reflectance data, are linearly related to the amount of photosynthetically active radiation absorbed by plant canopies (Asrar et al., 1984; Daughtry et al., 1992; Goward and Huemmrich, 1992; Johnson and Scholasch, 2005). Spectral indices such as the normalized difference vegetation index (NDVI), derived as the ratio of the difference and sum of reflectance in the NIR and red spectral regions, can effectively track spatially variable crop canopy development for particular crops in real time. However, broader applicability of the spectral technique across a wide range of horticultural crops is uncertain. This study addresses the relationship of remotely sensed NDVI relative to CC of several major horticultural crops in commercial fields with varying planting configurations and stages of maturity.

\section{Materials and Methods}

Study site. On 1 July 2005 and 19 to 20 June 2006, CC of 11 crops (seven annual and three perennial horticultural crops) was measured on the west side of the San Joaquin Valley in California. The 30 measured fields (Table 1) were located near Five Points, CA, within 10 miles of lat. $36^{\circ} 23^{\prime} \mathrm{N}$ and long. $120^{\circ} 12^{\prime} \mathrm{W}$. Soil textures in the study area ranged from sandy loam to clay loam soils and all soils were light-colored with low organic matter (less than $0.5 \%$ ). Most fields were drip-irrigated and essentially weed-free with a dry soil surface (less than 10\% volumetric water content) with some minor exceptions as noted in Table 1. Row orientation in all fields was north-south. Crops and fields were selected to represent a wide range of both perennial and annual horticultural crops with widely varying canopy structures and covers. Fields were selected that had uniform cropping patterns. Most fields were at least $200 \mathrm{~m}$ in the smallest dimension.

Canopy cover measurement. Canopy cover in each field was measured with a multispectral camera (TetraCam ADC; TetraCam, Chatsworth, CA) suspended from a frame directly above the crop and aimed vertically downward. The camera is a single-sensor digital camera (1.3-megapixel resolution) optimized for capture of red, green, and NIR wavelengths of reflected light. The digital photographs were analyzed with image-editing software (Pixelwrench and Briv32) provided by the camera manufacturer to differentiate between live vegetation and soil background and calculate the percentage of the photograph that contained live vegetation. The software assists the user in selecting threshold values based on red and NIR reflectance that separate live vegetation from background, displays the differentiated photograph, and calculates the percentage of the scene's pixels that contains live vegetation. Analysis of selected photographs by manually outlining vegetation and calculating areas with computer-assisted design software gave comparable results and indicated the validity of the process. Measurements were taken within $3 \mathrm{~h}$ of solar noon, although this was not a requirement of the technique. Figure 1 shows a TetraCam photograph of the canopy of the onion crop in field 6 .

The camera was suspended $2.3 \mathrm{~m}$ above the ground surface for low-growing crops (less than $0.5 \mathrm{~m}$ height) and $6.1 \mathrm{~m}$ above the ground surface for tall crops (vineyards and immature orchards) (Figs. 2 and 3). The photographs were cropped or scaled to contain a representative crop area (row width or plant spacing). For widely spaced tree crops, area of individual tree canopies was determined with the assistance of a physical scale (meter stick) suspended in the photograph at the height of the maximum canopy width. In 2005, two photographs were taken in each field and the CC measurements were averaged. In 2006, four photographs were taken per field and the measurements averaged and SDS calculated. The standard deviation of the four canopy measurements in 2006 varied from 0.003 to 0.067 and averaged 0.028 .

Dimensional measurements of the $\mathrm{CC}$ were made near the location where the TetraCam photographs were taken. These data were taken primarily to determine how closely these relatively simple and convenient measurements compared with photographic CC. A tape measure was used to measure crop row and plant spacing and to estimate plant canopy diameters or widths and height. Dimensional CC, CCd, was calculated either as canopy width divided 


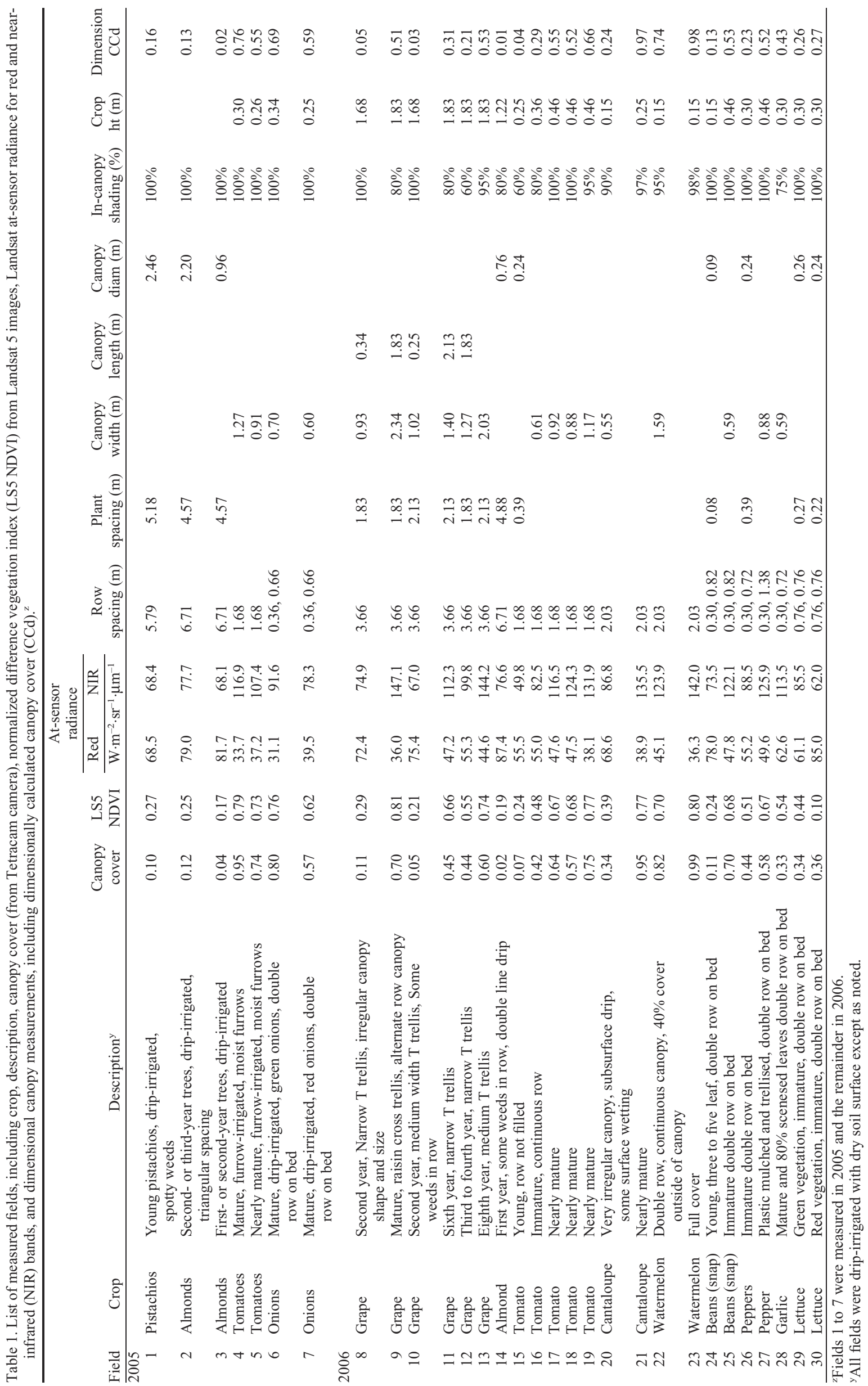


by row spacing when canopies were continuous in a row or on a bed or by the canopy size of individual plants based on either a circular or rectangular shape divided by plant spacing. The percentage of the shaded ground surface under the canopy ("in-canopy shading" in Table 1) was estimated visually to correct for canopy gaps.

NDVI measurement. Landsat 5 Thematic Mapper clear-sky satellite images of the study area for 1 July 2005 and 18 June 2006 were acquired from the U.S. Geological Survey Landsat Project (http://landsat.usgs. gov). The study fields were identified from global positioning satellite field coordinates and confirmed with aerial photographs. Landsat digital counts (DC) in the red and NIR channels were converted to at-sensor spectral radiance $\left(\mathrm{Ls} ; \mathrm{W} \cdot \mathrm{m}^{-2} \cdot \mathrm{sr}^{-1} \cdot \mu \mathrm{m}^{-1}\right.$ ) as:

$$
\mathrm{Ls}=\mathrm{DC} * \text { gain }+ \text { offset }
$$

using gain and offset calibration coefficients provided as scene metadata. The Modtran atmospheric radiative transfer model (Berk

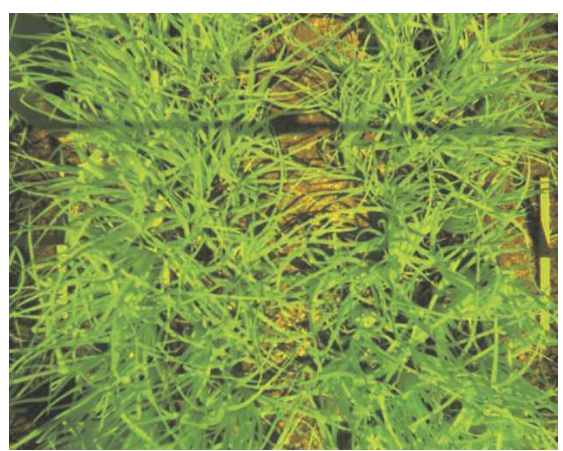

Fig. 1. Onion canopy for field 6 (canopy cover $=$ $0.80)$ captured by the TetraCam camera and processed by Pixelwrench and Briv32 software.

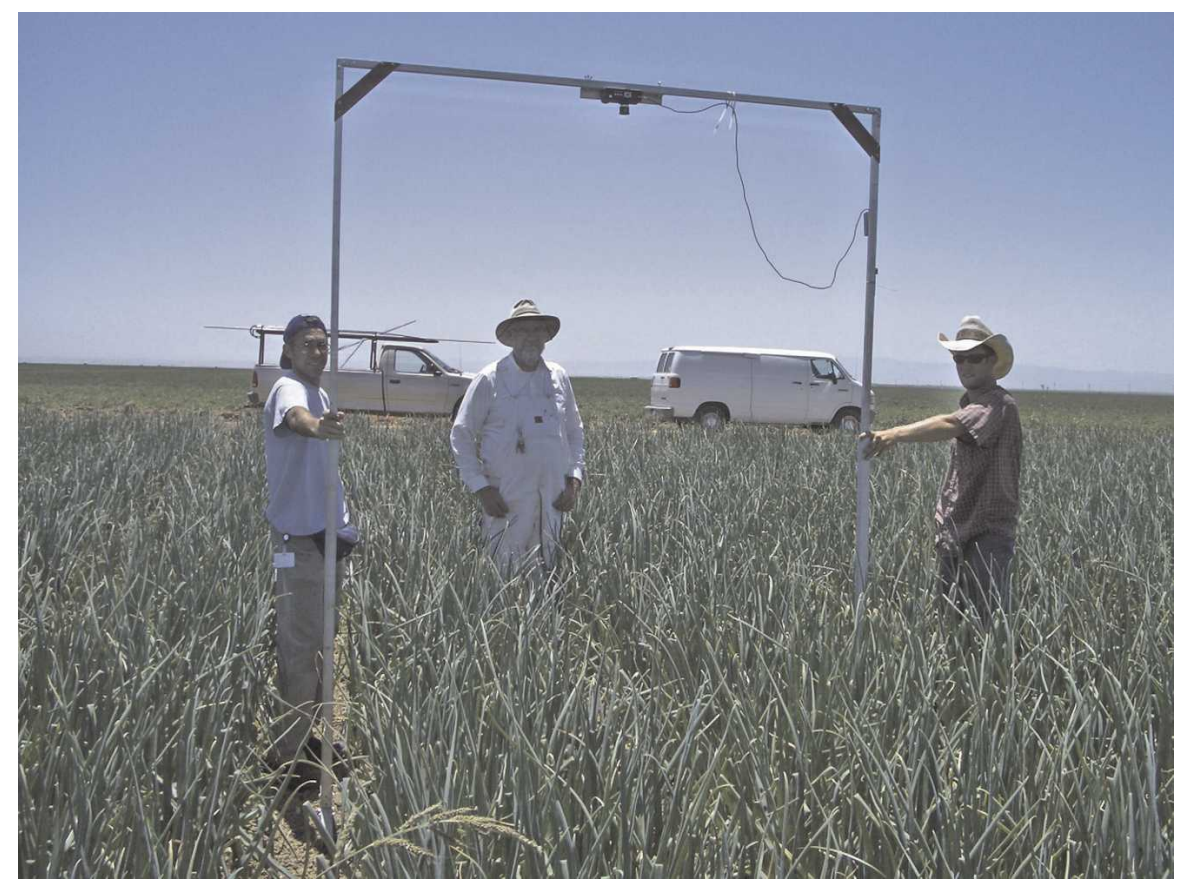

Fig. 2. Measurement of canopy cover for onion using the TetraCam camera on a 2.3-m stand.

et al., 2000) was then used to derive surface reflectance to account for atmospheric scattering/absorption, solar zenith angle, and spectral differences in top-of-atmosphere solar irradiance. Surface reflectance (SR) was calculated for the red and NIR bands as:

$$
\mathrm{SR}=\mathrm{a} *(\mathrm{Ls}-\mathrm{Lp}) /(\mathrm{La}-\mathrm{Lp})
$$

where Ls is observed at-sensor radiance, $\mathrm{La}$ is modeled total top-of-atmosphere radiance above a surface of constant nonzero albedo (a), set here to $50 \%$, and $\mathrm{Lp}$ is atmospheric path radiance or energy scattered back to the sensor by the atmosphere without surface interaction (after Green, 1990; Johnson et al., 1994). Atmospheric path radiance, Lp, was modeled as top-of-atmosphere radiance above a surface of zero albedo. A standard Modtran midlatitude summer atmospheric profile, with default $23 \mathrm{~km}$ horizontal visibility, was used to retrieve La and Lp for both acquisitions. The derived red and NIR surface reflectance values were then used to calculate the NDVI (Rouse et al., 1973; Tucker, 1979) as:

$\mathrm{NDVI}=\left(\mathrm{SR}_{\mathrm{NIR}}-\mathrm{SR}_{\text {red }}\right) /\left(\mathrm{SR}_{\mathrm{NIR}}+\mathrm{SR}_{\text {red }}\right)$

Landsat processing was performed with ERDAS Imagine 8.7 software (Leica Geosystems, St. Gallen, Switzerland). Average NDVI values were calculated for a $7 \times 7$ pixel area $(\approx 200 \times 200 \mathrm{~m})$ within each field. The standard deviation for the NDVI values for the 49 pixels varied from 0.01 to 0.08 and averaged 0.025 .

\section{Results}

The 30 measured fields included 10 with perennial crops (trees or vines) and 20 with annual crops (Table 1). Canopy cover mea- 


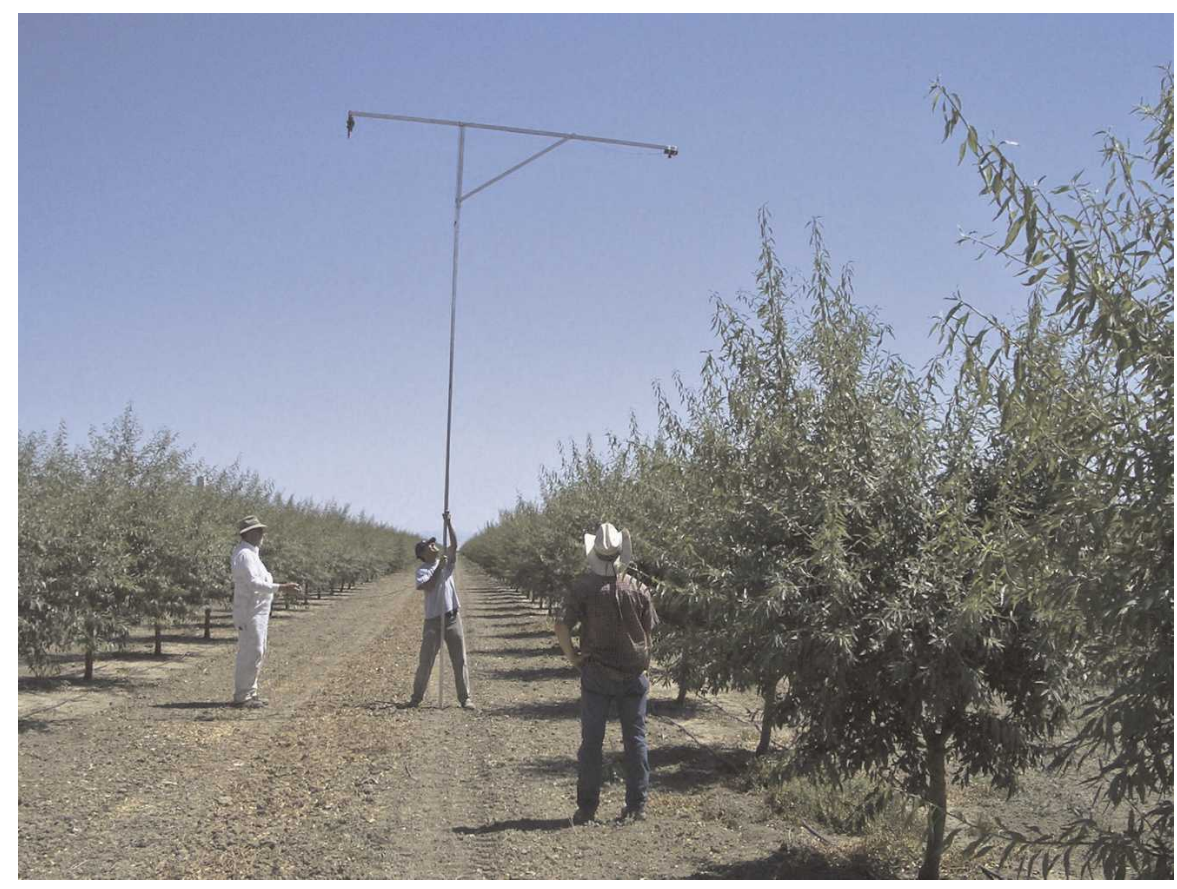

Fig. 3. Measurement of canopy cover on 2-year-old almond orchard using the TetraCam camera on a 6.1-m stand.

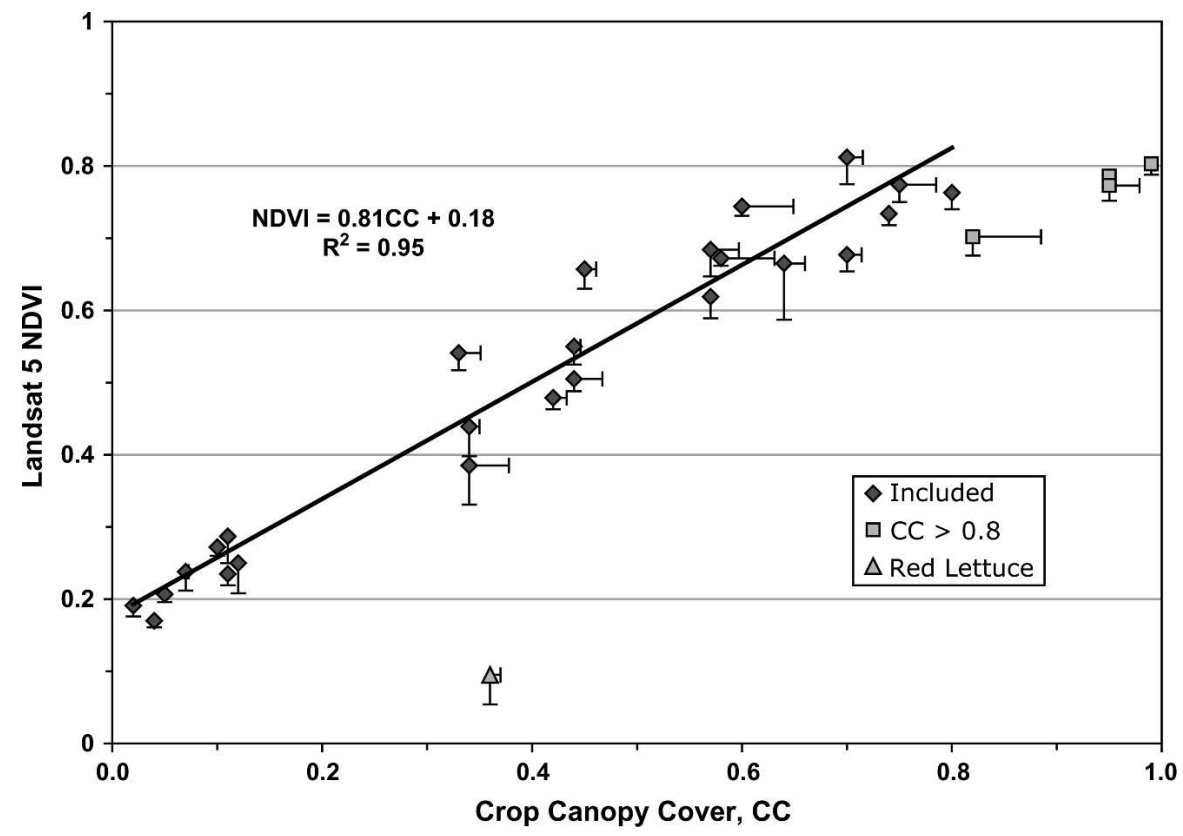

Fig. 4. Relationship between Landsat 5 normalized difference vegetation index and multispectral camera canopy cover (CC) and the linear regression line for the data represented by diamonds. Bars indicate SDS of the measurements. Squares represent high CC crops (greater than 0.8) and the triangle, field of red leaf lettuce.

Valley horticultural crops. The strong linear relationship between NDVI and CC, obtained over 2 years, is valid to a $\mathrm{CC}$ of 0.8 . The point at which NDVI begins to lose sensitivity generally corresponds to effective full cover (Neale et al., 2005), and water use does not appreciably increase for canopy cover above 0.8 (Doorenbos and Pruitt, 1977; Snyder et al., 2001). As demonstrated by the red leaf lettuce and garlic data, the NDVI:CC relationship presented here may not be valid for estimates, however, indicates that users should calibrate their dimensional measurements with photography or other objective techniques to improve accuracy.

Several studies have found that $\mathrm{CC}$ is related to the basal crop coefficient, $\mathrm{Kcb}$, used for predicting crop water use (Allen et al., 1998; Grattan et al., 1998; Trout and Gartung, 2006). With these two relationships (NDVI:CC and CC:Kcb) and estimates of soil evaporation and crop stress factors, water use of a wide range of crops over a wide region could be efficiently estimated from aerial or satellite based NDVI measurements and ground-based measurements of reference evapotranspiration, ETo. Several western U.S. states, including California, have weather station networks that provide daily ETo for important irrigated agricultural areas. By accounting for actual field conditions, this remote sensing method can provide better water requirement estimates than conventional, time-based crop coefficients (Bausch, 1995; Hunsaker et al., 2005). Ongoing data collection programs will improve confidence and precision in linking $\mathrm{CC}$ with crop water requirements.

Several options for remote sensing data collection are currently available. Landsat satellite images are collected every $16 \mathrm{~d}$ with $30-\mathrm{m}$ resolution, which is adequate resolution for most fields, can be acquired and processed within $24 \mathrm{~h}$, and cost only $\approx 1.5$ cents $/ \mathrm{km}^{2}$. NASA's MODIS satellite delivers NDVI data on a frequent basis with minimal delay and low cost, but its relatively coarse spatial resolution $(250 \mathrm{~m})$ may be appropriate only for very large fields or for regional assessments. High spatial resolution satellite imagery is available commercially, although costs can be relatively high and users must compete for instrument time.

In terms of operational use, disadvantages of satellite imagery for real-time CC estimates can include lack of frequency, cloud interference, delay in data availability, and low resolution (Moran et al., 1997). For the individual grower, aircraft may be a flexible and viable method of data collection, and several commercial companies supply airborne vegetation index products to agribusiness. Lack of frequency is the most difficult constraint to use of NDVI for irrigation scheduling. Some method would be required along with remote sensing images to interpolate between and extrapolate beyond available NDVI measurements. Crop simulation models are capable of estimating $\mathrm{CC}$ and can be "calibrated" for local field and climatic conditions with periodic NDVI measurements. Ground-based estimates of $\mathrm{CC}$ can also be used to interpolate and extrapolate CC between and beyond NDVI measurements. An optimal mapping scenario might involve collecting two to three remote sensing-based image observations of $\mathrm{CC}$ at key phenological times supplemented with ground-based observations or model predictions to complete the seasonal time series.

These results indicate that NDVI can potentially provide robust field-specific and 


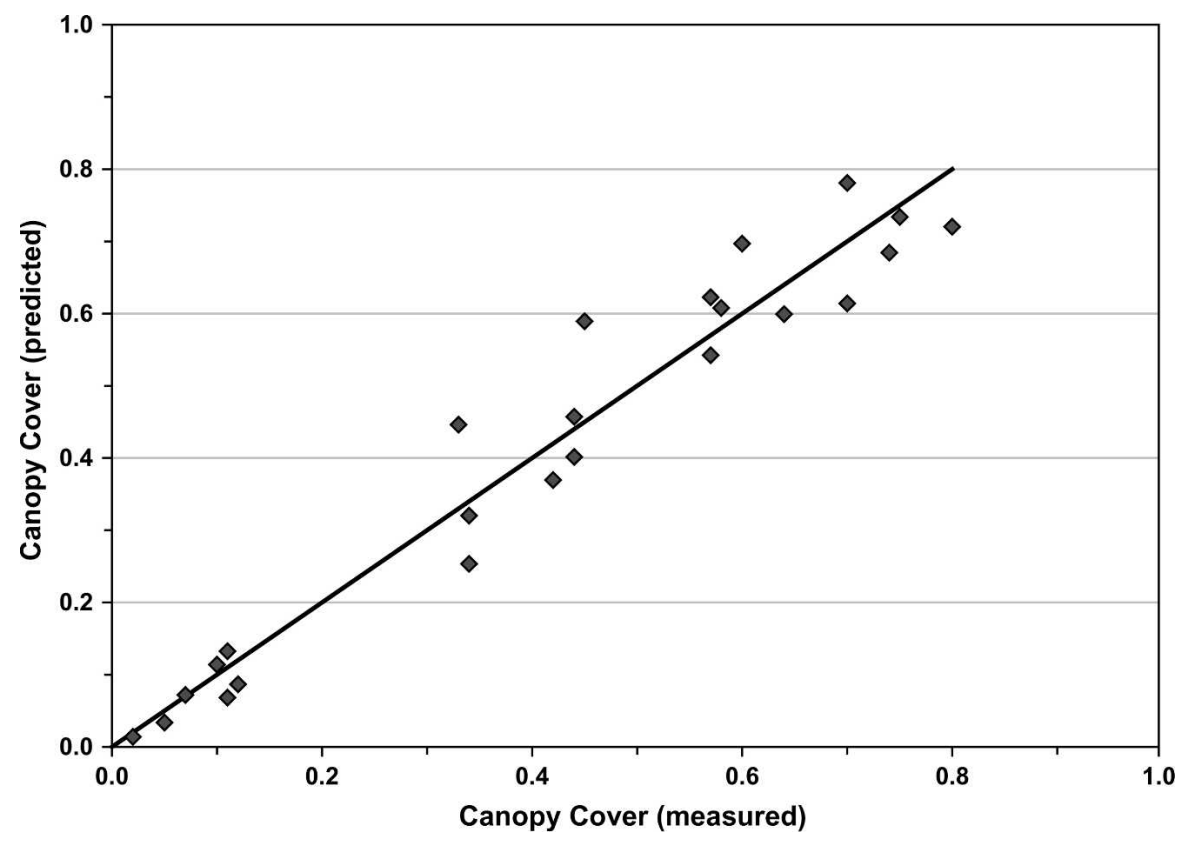

Fig. 5. Measured canopy cover versus canopy cover predicted by inversion of Figure 4 best-fit equation for 25 fields. One-to-one line shown for reference.

regional estimates of $\mathrm{CC}$ for horticultural crops with minimal requirement for supporting information. Such information may in turn serve to improve estimates of crop growth stage and water use in areas where ground-based reference ETo measurements are available.

\section{Literature Cited}

Allen, R.G., L.S. Pereira, D. Raes, and M. Smith. 1998. Crop evapotranspiration. FAO Irrig. and Drainage Paper \#56. FAO, Rome.

Asrar, G., M. Fuchs, E.T. Kanemasu, and J.L. Hatfield. 1984. Estimating absorbed photosynthetic radiation and leaf area index from spectral reflectance in wheat. Agron. J. 76:300306.

Bausch, W.C. 1995. Remote sensing of crop coefficients for improving the irrigation scheduling of corn. Agr. Water Manage. 27:55-68.

Berk, A., G.P. Anderson, P.K. Acharya, J.H. Chetwynd, M.L. Hoke, L.S. Bernstein, E.P. ter, p. 167-175. Proc. Second AVIRIS Workshop, JPL Publication 90-54, Pasadena, CA.

Heute, A.R. 1988. A soil-adjusted vegetation index (SAVI). Remote Sens. Environ. 25:295-309.

Hunsaker, D.J., E.M. Barnes, T.R. Clarke, G.J. Fitzgerald, and P.J. Pinter. 2005. Cotton irrigation scheduling using remotely sensed and FAO-56 basal crop coefficients. Trans. ASAE 48:1395-1407.

Johnson, L.F., C.A. Hlavka, and D.L. Peterson. 1994. Multivariate analysis of AVIRIS data for canopy biochemical estimation along the Oregon transect. Remote Sens. Environ. 47:216-230.

Johnson, L.F. and T. Scholasch. 2005. Remote sensing of shaded area in vineyards. HortTechnology 15:859-863.

Johnson, R.S., J. Ayars, and T. Hsiao. 2004 Improving a model for prediction peach tree evapotranspiration. Acta Horticultura. 664: 341-347.

Moran, M.S., Y. oue, and E.M. Barnes. 1997. Opportunities and limitation for image-based remote sensing in precision crop management. Remote Sens. Environ. 61:319-346.

NASS. 2002. 2002 census of agriculture. U.S. Dept. of Agriculture. 27 Dec. 2007. <http://www. nass.usda.gov/census/census02/volume $1 /$ us/ st99_1_002_002.pdfs.

Neale, C.M.U., H. Jayanthi, and J.L. Wright. 2005. Irrigation water management using high resolution airborne remote sensing. Irrig. and Drainage Syst. 19:321-336.

Rouse, J.W., R.H. Haas, J.A. Schell, and D.W. Deering. 1973. Monitoring vegetation systems in the Great Plains with ERTS. Proc. Third ERTS (Earth Resources Technology Satellite) Symposium, NASA SP-351. I:309-317.

Snyder, R.L., M. Orang, S. Matyac, and S. Eching. 2001. Crop coefficients. University of California. 27 Dec. 2007. <http://biomet.ucdavis.edu/ evapotranspiration/CropCoef/crop_coefficients. $\mathrm{htm}>$.

Trout, T.J. and J. Gartung. 2006. Use of crop canopy size to estimate crop coefficient for vegetable crops. Proc. 2006 World Environmental and Water Resources Congress, Omaha, NE, May 2006.

Tucker, C.J. 1979. Red and photographic infrared linear combinations for monitoring vegetation. Remote Sens. Environ. 8:127-150.

Williams, L.E. and J.E. Ayars. 2005. Grapevine water use and crop coefficient are linear functions of shaded area beneath the canopy. Agr. and Forest Met. 132:201-211. 